\title{
The lightwave road show
}

Erica Bricchi, Joanne Baggett, Denis Guilhot, Ian Musgrave

Erica Bricchi, Joanne C. Baggett, Denis A. Guilhot, lan O. Musgrave, "The lightwave road show," Proc. SPIE 9663, Eighth International Topical Meeting on Education and Training in Optics and Photonics, 96631L (6 October 2003); doi: $10.1117 / 12.2208469$

Event: Eighth International Topical Meeting on Education and Training in Optics and Photonics, 2003, Tucson, Arizona, United States 


\title{
The lightwave road show
}

\author{
Erica Bricchi, Joanne C. Baggett, Denis A. Guilhot, and Ian O. Musgrave \\ Optoelectronics Research Centre, University of Southampton, Southampton, United Kingdom SO17 1 BJ \\ telephone: 44 (0)23 8059 3138; fax: 44 (0)23 8059 3142; e-mail: erb@orc.soton.ac.uk
}

\begin{abstract}
In order to change the way that school children view physics, OSA's University of Southampton Student Chapter has developed an optic roadshow. By taking simple optics experiments and demonstrations to primary schools we aim to dispel the negative image of classroom science and help teachers to convey the fascination of physics.

(C)2003 Optical Society of America
\end{abstract}

OCIS codes: (000.2060) Education; (000.2690) General physics

In 1998, our student chapter was asked to construct a few simple optics experiments suitable for school children ranging in age from five to 11 . The experiments, built using equipment from the members' laboratories, were taken to a few local schools. The initial events were so successful that we decided to build a permanent set of optics experiments, christened the "Lightwave Road Show", which we fine-tune and expand each year. A website about the project, developed by former student chapter member Stephen Barrington has been created containing explanations of the underlying physics of some optical phenomena together with online instructions for experiments that can be done at home. This site was named the "best site of the week" by New Scientist magazine (www.lightwave.soton.ac.uk).

Every year during the National Science week, the equipment is installed in our department, the Optoelectronics Research Centre (ORC), and the local schools are invited to send children to attend the demonstrations. The student chapter members, with the help of many postgraduate students of the ORC, then take the show on the road to a number of schools. The members of the chapter perform the experiments, explaining to the students as they go along the physics involved.

The current version of the road show explores five areas of optics; mirrors, lenses, the spectrum, the eye and telecommunications. Each topic is illustrated by means of simple experiments and demonstrations which are accompanied by posters providing easy to understand explanations. Our primary goal is to generate interest and enthusiasm amongst the children and we therefore make an extra effort to ensure that the experiments are both interactive and visually attractive.

Depending on the size of the venue and the age of the children attending the show, we install the experiments in five independent sectors, or we make a smaller display and take a group of four or five children through each subject. In both cases, we demonstrate and supervise the larger experiments and leave the children free to explore the rest of the equipment and read the posters in their own time.

Over the years that the Lightwave Road Show has been running we have visited many local primary schools, science fairs and regularly set-up the road show experiments at the university for visiting children and parents. The reaction of the children, parents and teachers is always overwhelming and the show is constantly in demand. This response is extremely rewarding and confirms that we are succeeding in our goal to show that physics is both fun and highly relevant to everyday life.

Eighth International Topical Meeting on Education and Training in Optics and Photonics,

edited by Barry L. Shoop, Grover Swartzlander Jr., Proc. of SPIE Vol. 9663, 96631L

(C) 2003 SPIE, OSA, ICO · doi: 10.1117/12.2208469 